\title{
Local safety and security planning in Finland
}

\author{
R. Molarius ${ }^{1}$, J. Keränen ${ }^{1}$, H. Kojo ${ }^{1}$ \& J. Wallenius ${ }^{2}$ \\ ${ }^{I}$ VTT Technical Research Centre of Finland, Finland \\ ${ }^{2}$ Awanic Oy, Finland
}

\begin{abstract}
Local community safety and security planning is considered an effective tool to increase the security of citizens. When the Ministry of the Interior launched a new internal safety programme in 2004 , it also decided to provide support to the regional authorities to prepare these plans. For this reason, VTT Technical Research Centre of Finland was asked to develop a common method and tool to identify and assess local threats. The developed method classifies threats in seven safety and security areas. In some of these, such as general vulnerability, criminality and major accidents, the method finds out which issues threaten people in their everyday lives. Some areas, such as disturbances and social exclusion, are regarded as consequences of other trouble, and the aim is to find the root causes of them. The method was established as a web-based software tool called ARTU.
\end{abstract}

Keywords: community safety plans, safe community, web-based threat analyses, Finland.

\section{Introduction}

The preparation of a community safety and security plan has been in place in Finland since 1999. The work started as part of the national crime prevention programme authorized by the Ministry of the Interior. Although the main aim of this programme was to prevent violence and crime, in many cases, the outcome was a broader view of general safety and wellbeing.

The first Internal Safety and Security Programme was launched by the Government on 24 September 2004 [1]. The aim was to raise Finland to the safest country in Europe by 2015 by increasing safety and security in everyday life. Internal safety and security is defined as 'a state of society where everyone can enjoy the rights and freedoms guaranteed by the rule of law and a safe 
society without the fear or insecurity caused by crime, disruptions, accidents or any other phenomena in Finnish society' [2].

Internal safety and security involve several factors, which, in parallel, achieve the best results. A good working environment reduces the risk of occupational accidents, improvements in living conditions for socially excluded people, such as the poor, immigrants and the homeless, reduce crime [3-5], and well-designed basic services, such as health, police and rescue services, help people feel safe and enhance the social capital and trust in the government [6]. One of the most challenging issues is to reduce accidents in the home and in leisure time. Today, these are among the most serious incidents for 16-65-year-olds in everyday life in Finland (Figure 1).

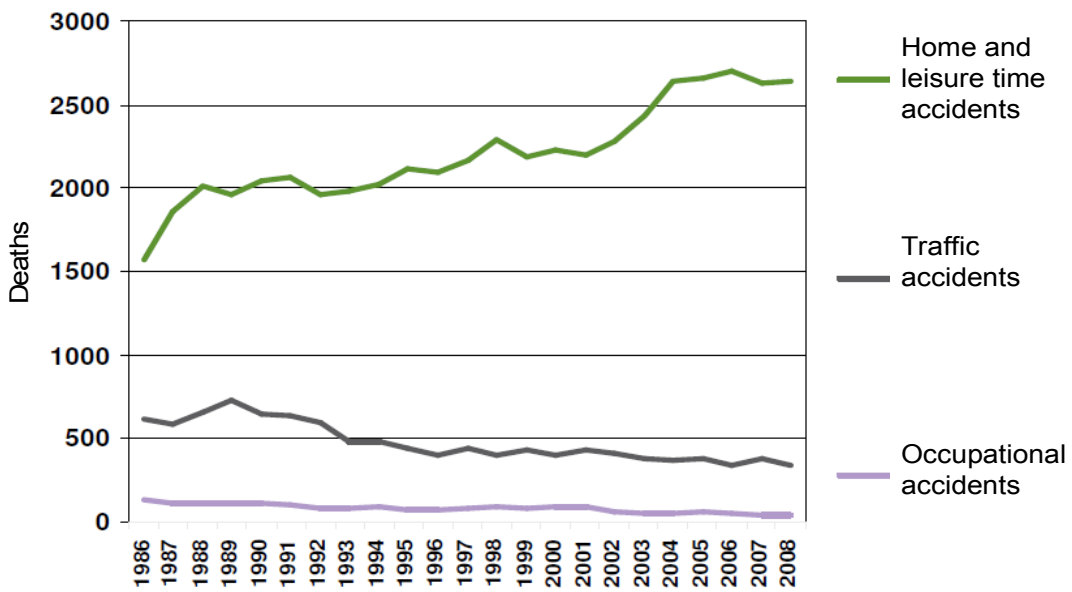

Figure 1: Accidents ending in death for 16-65-year-olds in Finland 19862008 [7].

The purpose of the internal safety and security programme is to enhance the safety of individuals by increasing security in everyday life. Safety and security are achieved through a well-run public sector that concentrates on proactive, preventive work. While the earlier security plans concentrated on crime prevention, new areas such as traffic safety, border security and prevention of accidents and disturbances are now included.

\section{Community safety and security planning}

Community safety and security plans are managed by local authorities [8]. The main responsibility for implementing the plans is given to the local police authority. Persons from the three core authorities, the chief of police, 
representatives from the rescue services and the management of the municipalities, are instructed to steer the work. The first meeting is summoned by the chief of police.

The core group manages the preparations for the community safety and security plans and makes decisions on the common goals and the organization of the co-operation between the authorities and voluntary organizations such as the Red Cross, the Child Welfare Association, the Church, the life-saving services, traffic safety associations, etc. It is also responsible for following up the results and reporting them inside the community and to the Ministry of the Interior.

The first task is to identify the threats and risks to be managed. A local risk analysis of the operational environment must therefore be carried out. It is important that all actors that are able to help and provide results to handle and manage the risks and threats are involved in the planning act. Different kinds of actors are needed in different local areas.

To ensure that the causes and effects are analysed thoroughly, the work crosses the borders of administration units and involves the private sector, voluntary organizations and other interest groups.

The process is shown in Figure 2, and it is the same in different parts of Finland. Finland is now divided into 24 governmental police areas, 22 rescue service areas and 336 municipalities. Due to this complex structure, the community safety and security plans cover diverse concepts for the police,

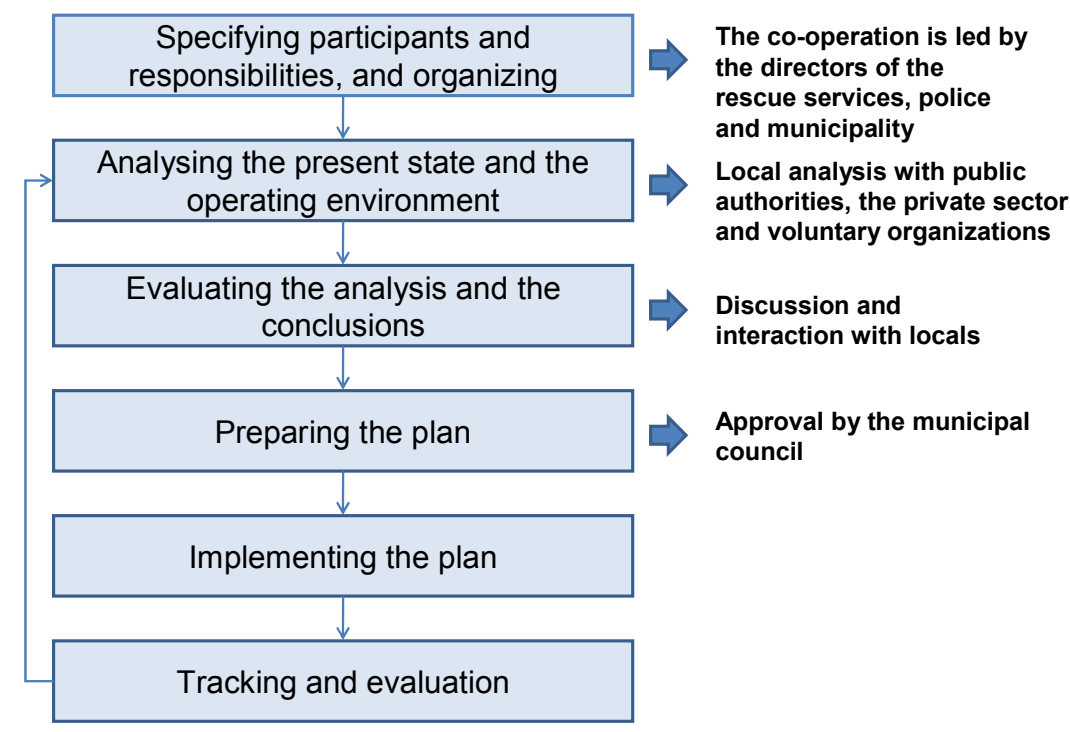

Figure 2: The process community safety and security planning in Finland; taken from [9]. 
rescue services and municipal areas. Cities with more than 200,000 inhabitants usually produce their own plans, but in some rural areas, there may only be one plan for 20 municipal areas.

\section{Tool for community planning}

To provide support to the security planning process, the Ministry of the Interior ordered a software tool called ARTU from VTT Technical Research Centre of Finland.

The main idea was to ensure that the preparation for the operational environment analysis was easy and systematic. At the same time, the webbrowser-based application collected all the risk information into one programme. Hence, the information is on hand for local analysis as well as national analysis and research activities.

The ARTU is a web-based tool for assessing local threat analyses. With a web-based approach, the work is not restricted to one place but can be carried out wherever an Internet connection is available. ARTU covers all the steps of the security and safety planning process almost fully, and it thus ensures that the planning is done systematically.

\subsection{Use of the tool}

The ARTU tool is ordered from the Ministry of the Interior, and the rights are given only to the police authorities. Their first step is to gather the core group and then, together with the core group, to specify the areas to be analysed. These areas may be geographical or functional, such as traffic safety, safety at home, marginalization, etc. This allows, for example, a larger commune to divide its area into smaller evaluation areas or establish different working groups to find threats in their specific areas of expertise rather than to try to cover the whole analysis at once.

Next, the core group brings together suitable risk analysis groups to prepare for the analyses of the operational environments. While bringing together these groups, the police authority can assign group leader and/or group member rights in the ARTU tool for its planning area only. The ARTU tool is designed to progress in parallel with the decision-making process and hence the given rights also show the hierarchy of decision-making. The core group also has rights to follow all the discussions that take place through ARTU at the lower levels.

The identification of threats is made in the group areas, which are also able to classify the risks according to their likelihood and severity. The identification phase usually brings up a large number of possible threats, many of which are small and demand no action. The evaluation groups may be included in or excluded from the planning work, according to the special features of the analysed area. The classification helps to locate the most significant threats and to concentrate the safety and security planning on them.

The risk identification groups are also allowed to propose actions to manage the identified risks. Each local planning group is able to formulate a separate risk 
evaluation group to go through all the risks that have been found and evaluate them in a coherent way. The tool also features action planning and tracking of planned actions to remove or reduce threats. With the tool, it is possible to follow the way the actions are executed, if they are on schedule and who is responsible for them. Different reports and summaries are available, according to the users' needs, and once the threat analysis has been completed, it is easy to update it regularly or to evaluate certain parts again when necessary.

The community safety and security plan shall be prepared every fourth year and provide advice for the work by the municipal executive board. The work shall be arranged in parallel with the municipal electoral period.

One of the tool's strengths is that it can be used to create co-operation and discussion between different authorities and voluntary associations. It has been shown that no safety or security work is successful unless all the organizations and associations involved work together towards the same goal.

\subsection{Content of the tool}

The ARTU tool covers seven safety and security areas that have been found to be linked to the safety of everyday life (Figure 3). In five of them, general vulnerability, criminality, major accidents and insecurity, the main riskidentification question is 'Which issues threaten the citizens' safety and security

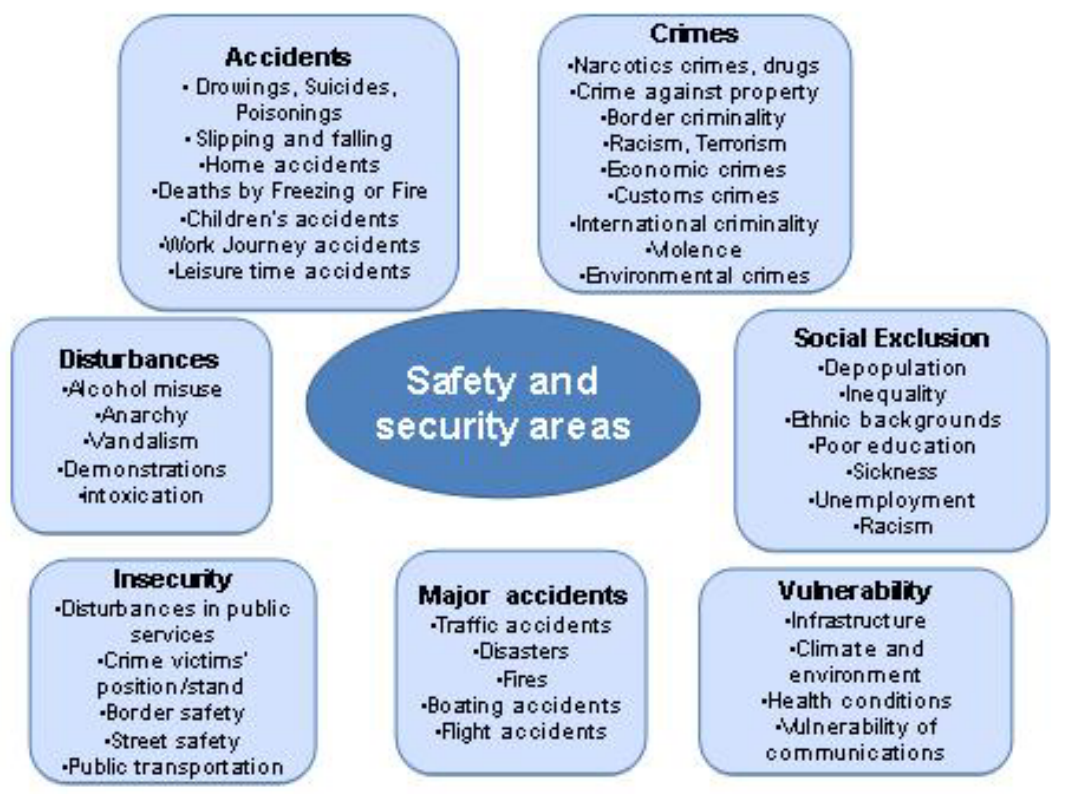

Figure 3: The seven areas of safety and security in community safety and security plan. 
in everyday life?' The last two areas, disturbances and social exclusion, are regarded as consequences of other troubles, and the question is 'Which incidents or issues can lead to disturbances and social exclusion?' This divided approach with reasons and consequences ensures that all the important threats are found and processed.

All seven safety and security areas are divided into more precise groups for threat identification and classification. For example, the 'Major accidents' area includes groups such as flight, traffic and boating accidents, fires and disasters, and the 'Insecurity' area includes everything from disturbances in public services to the position of crime victims. In the tool, in addition to these 7 main areas, there are more than 70 sub-areas to channel the work into the most important issues.

\section{Results}

The local safety and security planning, in its current form, began in 2004. The municipalities have been involved in the planning work since then, and most of them have only prepared one plan for the operating season 2008-2012. According to the government's guidelines, the safety and security plans must be prepared when the new municipal executive board starts its work, so the next planning season will start in 2012.

In light of the statistics, the community safety and security plans have not yet succeeded in reducing crime or increasing the feeling of safety. For example, the study of safety in the twenty biggest towns shows that the number of crimes is at about the same level as in 2004, and the number of incidents of grievous bodily harm and drug crime has actually increased [10]. The rate of occupational and traffic accidents has decreased, however, as has the rate of home and leisure accidents, since 2006 (Figure 1), so, the work has just started.

During the last planning season, most of the plans were done manually without any systematic planning programme. As the ARTU tool was quite new at the time of the last planning season, it only supported the local planning work in a few areas. The power of this kind of tool will therefore not be seen before the next planning season.

\section{Conclusions}

Community safety and security planning started in Finland as comprehensive cooperation between several authorities and voluntary organizations in the beginning of 2005. Since then, the police authorities have coordinated the preparation of several local safety and security plans, each of which covers from one to twenty separate municipalities. The work has different focuses depending on the safety situation of each area.

The ARTU tool was developed to enhance the co-operation of the development work between the authorities and the voluntary organizations. At the same time, the tool can collect the safety information from different parts of the state into one database. 
Due to the municipal electoral periods (four years), only one full-time planning season has been completed, and there is therefore no clear picture of the benefits of the planning procedure or the supporting ARTU tool. We are ready to develop the tool to support the planning procedure even better, however, as we believe that the safety and security of the communities will not improve without close co-operation between the authorities and voluntary organizations, and the tool may be the best way to do so.

\section{References}

[1] Ministry of the Interior Finland. Everyday Safety. Internal Security Programme in 2004 (in Finnish). ISBN 951-734-763-4 (pdf) 2004. http://www.intermin.fi/intermin/biblio.nsf/6999D85A980CD058C2256F18 0034DCC8/\$file/442004.pdf

[2] Ministry of the Interior Finland. Safety first. Internal Security Programme (in 2008). Publications 25/2008. ISBN 978-952-492-365-2 (pdf). 2008. http://www.intermin.fi/intermin/hankkeet/turva/home.nsf/files/252008\%20 ENG/\$file/252008\%20ENG.pdf

[3] Kekki T. Habitual criminality, drugs and crime continuum (in Finnish). Studies of Police College of Finland. 80 / 2009.

[4] Parikka R. The long shadow - Unfortunality as a historical continuum (in Finnish). In unfortunality and the change in a welfare state. (Ed. Heikkilä M and Vähätalo K., Gaudeamus. Helsinki, 1994. pp 51-89.

[5] Bausman K. and Goe R. An Examination of the Link Between Employment Volatility and the Spatial Distribution of Property Crime Rates. American Journal of Economics and Sociology. Vol 63. Issue 3. pp. 665-696. 2004.

[6] Rothstein B. and Stolle D. The Quality of Government and Social Capital: A Theory of Political Institutions and Generalized Trust. QoG Working Paper series 2007:2. The Quality of Government Institute. Göteborg Universitet. ISSN 1653-8919. 2007.

[7] Statistics of Finland. Statistics of Cause of Death, Road Accidents and Accidents at Work. Collected by the National Institute of Health and Welfare http://www.ktl.fi/portal/suomi/yhteistyoprojektit/tapaturmat/tapaturmat_luk uina/kuolemansyyt_2008/ (in Finnish).

[8] Mimicry of Interior Finland. The development of local safety and security work (in Finnish). Publications 19/2006. ISBN 951-734-964-5. 2006. http://www.intermin.fi/intermin/biblio.nsf/B9270743C6457188C22571470 02DACFC/\$file/192006.pdf

[9] Ministry of the Interior Finland. The development of local safety and security work (in Finnish). Publications 19/2006. ISBN 951-734-964-5. 2006.

http://www.intermin.fi/intermin/biblio.nsf/B9270743C6457188C22571470 02DACFC/\$file/192006.pdf 
136 Safety and Security Engineering IV

[10] Ministry of the Interior, Finland. The safety of the cities (in Finnish). Publications 33/2010 (Draft version). http://www.intermin.fi/intermin /hankkeet/turva/home.nsf/files/Kaupunkien\%20turvallisuusohjelma\%20julk aisupohjalla\%2030\%2011\%202010/\$file/Kaupunkien\%20turvallisuusohjel ma\%20julkaisupohjalla\%2030\%2011\%202010.pdf 